\title{
Effect of L. plantarum cell-free extract and co-trimoxazole against Salmonella Typhimurium: a possible adjunct therapy
}

\author{
Praveen Rishi*, Simran Preet, Prabhjot Kaur
}

\begin{abstract}
Background: Frequent and indiscriminate use of antibiotics has led to the development of multi-drug resistant bacterial strains. It necessitates the exploitation of alternative therapeutic strategies. In order to reduce the dose of antibiotic required and to decrease the associated side effects, the present study was aimed at evaluating the synergism, if any, between a conventional antibiotic, co-trimoxazole (CTZ)) and cell free supernatant (CFS) of a probiotic (L. plantarum) against S. Typhimurium NCTC 74. This antimicrobial combination was selected on the basis of antibiotic susceptibility pattern of Salmonella and L. plantarum.

Methods: The synergy was evaluated in terms of size of zone of inhibition, fractional inhibitory concentration index, time-kill assay (in-vitro) as well as macrophage functions (ex-vivo).

Results: The concentration producing the same or higher antibacterial effect (size of zone of inhibition) was reduced to half when both the agents were used in combination with respect to the concentrations required when used separately. CTZ and CFS exhibited synergetic activity against Salmonella by checkerboard microtitre test and the time-kill test. Ex-vivo studies demonstrated a significantly higher intracellular killing of bacteria by macrophages treated with CFS $(80 \mathrm{AU} / \mathrm{ml})+(\mathrm{CTZ})(2 \mu \mathrm{g} / \mathrm{ml})$ as compared to when treated with both separately at higher concentrations. Significant reduction in the extent of lipid peroxidation and nitrite levels generated by macrophages in presence of CFS and CTZ, in conjunction, further substantiated the synergistic efficacy of the combination.
\end{abstract}

Conclusions: The antimicrobial efficacy of this combination indicates that it may serve as the basis in developing alternative strategies to combat Salmonella infections.

\section{Background}

Salmonella infections cause a great deal of morbidity and mortality worldwide, especially in developing countries because of improper sanitary conditions and inadequate health facilities. Antibiotics have been the mainstay of therapy to combat Salmonella infections. However, the use of antibiotics is under question due to complications involving the emergence of multidrug (MDR) resistant strains of Salmonella [1,2]. Besides this, frequent and lengthy use of antibiotics usually results in alteration of the intestinal commensal flora [3] and lead to chronic toxicity. It necessitates the exploitation of

\footnotetext{
* Correspondence: rishipraveen@yahoo.com

Department of Microbiology, Basic Medical Sciences Block, Panjab University, Sector-14, Chandigarh-160014, India
}

(C) 2011 Rishi et al; licensee BioMed Central Ltd. This is an Open Access article distributed under the terms of the Creative Commons Attribution License (http://creativecommons.org/licenses/by/2.0), which permits unrestricted use, distribution, and reproduction in any medium, provided the original work is properly cited. alternative antibacterial therapies against Salmonella infections. Synergistic combinations of antibiotics and other antimicrobials may be effective not only against infections where the development of resistance and/or subsequent failure to monotherapy is prevalent but also in prevention of emergence of bacterial resistance [4]. One such alternative is the possible therapeutic use of probiotics as an adjunct to chemotherapy [5].

Probiotics are dietary supplements containing potentially beneficial bacteria or yeasts. According to the currently adopted definition by FAO/WHO in 2001, probiotics are 'live microorganisms, which when administered in adequate amounts confer a health benefit on the host' [6]. The role of probiotics has been reported in prevention and treatment of gastrointestinal infections caused by Salmonella [7,8], rotavirus and Clostridium 
difficile [9-11]. Probiotics in combination with antibiotic treatment have been reported to be successful in the management of Helicobacter pylori infection [12].

Probiotic and antibiotic combinatorial therapy may provide higher antimicrobial activity and reduce the dose of antibiotic required besides replenishing the intestinal flora thereby providing benefit to the host [13]. The present study was therefore carried out to assess the in-vitro and ex-vivo synergistic effect, if any, of cell-free Lactobacillus plantarum supernatant (CFS) in conjunction with co-trimoxazole (CTZ) against Salmonella Typhimurium.

\section{Methods}

Bacterial strains and growth conditions

Lactobacillus casei MTCC 1423, Lactobacillus plantarum MTCC 2621 and Lactobacillus acidophilus MTCC 447, standard LAB strains were procured from Institute of Microbial Technology (IMTECH), Chandigarh, India. Salmonella enterica serovar Typhimurium NCTC74 was procured from the Central Research Institute (CRI), Kasauli. This strain has been used in previous studies both as a virulent strain [14] and as a reference strain [15].

\section{Growth Conditions}

Salmonella Typhimurium was maintained on Brain Heart Infusion Broth and sub-cultured bimonthly. It was grown on nutrient broth for $18 \mathrm{~h}$ at $37^{\circ} \mathrm{C}$. After centrifugation, the culture was harvested in phosphatebuffered saline (PBS) and adjusted to a final cell count of approx. $4 \times 10^{7} \mathrm{CFU} / \mathrm{ml}$. Lactobacilli strains were grown in De Mann Rogosa Sharpe (MRS) broth for $24 \mathrm{~h}$ and adjusted to a final concentration of approx. $9 \times 10^{8} \mathrm{CFU} / \mathrm{ml}$. The bacterial strains used in the present study were confirmed by their morphological and biochemical characteristics.

\section{Antibiotic susceptibility tests}

All procured strains were tested for their susceptibility to various antibiotics $(\mu \mathrm{g})$ : Cotrimoxazole (25); Gentamycin (10); Ampicillin (25); Cephalexin (30); Norfloxacin (10); Amikacin (30); Cefoxitin (10); Chloramphenicol (10); Cefuroxine (30); Augmentin (10); Cefotaxime (30); Ciprofloxacin (10) and Tetracycline (25) by the method of Bauer et al. [16]. $10^{6}$ colony forming units (CFUs) of each Lactobacillus strain were spread plated individually onto MRS agar plate. Hi-media octadiscs impregnated with antibiotics were placed on the surface of the agar plates. The plates were incubated at $37^{\circ} \mathrm{C}$ for $18-24 \mathrm{hrs}$ and examined for the zones of inhibition appearing around each antibiotic disc. The experiment was repeated thrice and the average inhibitory zone diameters were compared with the standards provided by the National Committee for Clinical Laboratory Standards (NCCLS) [17]. Antibiotic sensitivity of Salmonella Typhimurium was also determined by the same method using nutrient agar plates.

\section{Agar well diffusion assay (agar-WDA)}

As the antibiotic susceptibility pattern indicated that Lactobacillus plantarum was resistant and Salmonella Typhimurium was sensitive to co-trimoxazole, the feasibility of using this combination was further confirmed by agar-WDA [18]. $10^{7} \mathrm{CFU}$ of L. plantarum and $S$. Typhimurium were spread plated on MRS and nutrient agar plates respectively. Wells of $5 \mathrm{~mm}$ diameter were punched in the agar plates and filled with $20 \mu \mathrm{l}$ co-trimoxazole stock solution $(1 \mathrm{mg} / \mathrm{ml})$. The plates were then incubated at $37^{\circ} \mathrm{C}$ for $24 \mathrm{~h}$ and observed for the zones of inhibition around the wells.

\section{Preparation of cell free supernatant (CFS) from L. plantarum}

CFS was prepared as described by Ogunbanwo et al. [19]. L. plantarum was propagated in 1L MRS broth $\left(\mathrm{pH}\right.$ 6.5) for 24 hours at $37^{\circ} \mathrm{C}$. Cell free supernatant obtained by centrifuging the culture at $10,000 \mathrm{rpm}$ for 20 minutes at $4^{\circ} \mathrm{C}$ was filtered through $0.22 \mu \mathrm{m}$ pore size cellulose acetate filter.

\section{Quantification of antagonistic activity of CFS against Salmonella Typhimurium}

The antibacterial activity of CFS against $S$. Typhimurium was tested at twofold serial dilutions using agarWDA as described above. For this experiment, wells were filled with $10 \mu \mathrm{l}$ of each CFS dilution and the antibacterial activity was expressed in terms of arbitrary unit (AU). It was defined as the maximum dilution which produced a minimum of zone that still gave a clearly visible antibacterial zone. The reciprocal of the dilution gave the titre of antibacterial activity in AU per $\mathrm{mm}[20]$.

\section{In-vitro inhibitory effect of CFS and co-trimoxazole Agar-well diffusion assay}

Nutrient agar plates were spread plated with approx. $10^{6}$ CFUs of $S$. Typhimurium and the wells were filled with $20 \mu \mathrm{l}$ solution containing various concentrations of CTZ $(10 \mu \mathrm{g} / \mathrm{ml}, 20 \mu \mathrm{g} / \mathrm{ml}, 30 \mu \mathrm{g} / \mathrm{ml})$ and CFS $(12 \mathrm{AU} / \mathrm{ml}$, $16 \mathrm{AU} / \mathrm{ml}$ and $20 \mathrm{AU} / \mathrm{ml}$ ) separately as well as in combination of both at half the concentrations i.e. (CTZ $(5 \mu \mathrm{g} / \mathrm{ml})+$ CFS $(6 \mathrm{AU} / \mathrm{ml}) ; \mathrm{CTZ}(10 \mu \mathrm{g} / \mathrm{ml})+$ CFS $(8 \mathrm{AU} / \mathrm{ml})$ and CTZ $(15 \mu \mathrm{g} / \mathrm{ml})+$ CFS $(10 \mathrm{AU} / \mathrm{ml})$. After incubation at $37^{\circ} \mathrm{C}$ for $24 \mathrm{~h}$, diameter of the clear zones around the wells was measured. 
Determination of minimum inhibitory concentrations (MICs)

The minimum inhibitory concentrations (MICs) of CFS and co-trimoxazole against $S$. typhimurium were determined by broth micro-dilution method. Co-trimoxazole powder (Torque Pharmaceuticals, India) was dissolved at a maximum concentration of $1 \mathrm{mg} / \mathrm{ml}$ in distilled water for MIC determination. The maximum concentration of CFS was $1280 \mathrm{AU} / \mathrm{ml}$ for MIC determination. Co-trimoxazole and CFS were subjected to a two-fold dilution series with Mueller-Hinton Broth and LB medium respectively. $10 \mu \mathrm{l}$ of each diluted solution was added in micro-titre plate wells. Then $90 \mu \mathrm{l}$ of $S$. Typhimurium cell suspension adjusted to $10^{6} \mathrm{cfu} / \mathrm{ml}$ was added to the wells and microtitre plate was incubated for $24 \mathrm{~h}$ at $37^{\circ} \mathrm{C}$. The lowest concentration that completely inhibited microbial growth as determined by optical density measurements at $600 \mathrm{~nm}$ was taken to be the MIC.

Synergistic activity of co-trimoxazole and CFS on checkerboard micro-titre test

Checkerboard test was performed in 96-well micro-titre trays using an 8.8 well configuration. Eight 2 -fold serial dilutions of co-trimoxazole and CFS were prepared with concentrations ranging from 0 to $2 \mathrm{MIC}$. $10 \mu \mathrm{l}$ of $\mathrm{CTZ}$ dilution was added to the wells of a 96-well plate in a vertical orientation and $10 \mu \mathrm{l}$ of each CFS dilution was added in a horizontal orientation so that the plate contained various concentrations of combinations of the two compounds. Then each well was supplemented with $80 \mu \mathrm{l}\left(10^{6} \mathrm{CFU} /\right.$ $\mathrm{ml}$ ) of $S$. Typhimurium and the plate was incubated at $37^{\circ} \mathrm{C}$. Wells not containing any antibacterial agent were used as the positive growth controls. Fractional inhibitory concentration (FIC) was calculated by dividing the MIC of the combination of CFS and CTZ by the MIC of CFS or cotrimoxazole alone. The FIC index (FICI), obtained by adding both FIC, was interpreted as indicating a synergistic effect when it was $\leq 0.5$, as additive or indifferent when it was $>0.5$ and $\leq 2.0$, and as antagonistic when it was > 2.0 [21].

\section{Time-kill Assay}

To determine the bactericidal action of co-trimoxazole and CFS, separately and in combination, $S$. Typhimurium was exposed to one of the antimicrobial agents or to both simultaneously and the viable count was monitored. Cotrimoxazole $(2 \mu \mathrm{g} / \mathrm{ml})$, CFS $(80 \mathrm{AU} / \mathrm{ml})$ and their combination were added to different $20 \mathrm{ml}$ nutrient broth flasks containing $10^{6}$ CFUs of $S$. Typhimurium and incubated at $37^{\circ} \mathrm{C} .100 \mu \mathrm{l}$ aliquots were withdrawn at at $0 \mathrm{~h}, 4 \mathrm{~h}, 8 \mathrm{~h}, 12$ h, 24 h, 28 h, 32 h, 36 h, 48 h and spread plated on MacConkey agar plates. The plates were incubated at $37^{\circ} \mathrm{C}$ for 24 hours for enumeration of colony forming units.

\section{Ex-vivo effect of CFS and co-trimoxazole}

Extraction of peritoneal macrophages: Murine peritoneal macrophages were isolated by the method as described by us earlier [14].

\section{Intracellular killing of S. Typhimurium}

Mouse peritoneal macrophages were infected with $S$. Typhimurium at a multiplicity of infection of $1: 100$. Extensively washed infected macrophages were treated with minimum inhibitory concentration of both i.e. CFS (640 AU/ml) and co-trimoxazole $(8 \mu \mathrm{g} / \mathrm{ml})$ separately and in combination as per fractional inhibitory concentrations i.e. (CFS $(80 \mathrm{AU} / \mathrm{ml})+\mathrm{CTZ}(2 \mu \mathrm{g} / \mathrm{ml}))$. After every 30, 60 and $90 \mathrm{~min}$ of treatment period, treated and untreated macrophages were pelleted $(2000 \mathrm{rpm}$, $10 \mathrm{~min}$ ) and lysed with $500 \mu \mathrm{l}$ of $0.25 \%$ TritonX-100. Lysates were serially diluted and plated on MacConkey agar medium. After an incubation of $24 \mathrm{~h}$ at $37^{\circ} \mathrm{C}$, CFUs were counted [14].

\section{Interaction of macrophages with S. Typhimurium}

To assess the extent of lipid peroxidation and to measure the nitric oxide generation, murine peritoneal macrophages were interacted with Salmonella (MOI of 1:100) in various groups: Group A: $1.5 \mathrm{ml}$ of macrophage suspension $\left(10^{5} / \mathrm{ml}\right)+0.8 \mathrm{ml}$ of $S$. Typhimurium cell suspension $\left(10^{7} / \mathrm{ml}\right)$; Group B: $1.5 \mathrm{ml}$ of macrophage suspension $\left(10^{5} / \mathrm{ml}\right)+0.8 \mathrm{ml}$ of $S$. Typhimurium cell suspension $\left(10^{7} / \mathrm{ml}\right)+$ CFS $(640 \mathrm{AU} / \mathrm{ml})$; Group C: $1.5 \mathrm{ml}$ of macrophage suspension $\left(10^{5} / \mathrm{ml}\right)+0.8 \mathrm{ml}$ of $S$. Typhimurium cell suspension $\left(10^{7} / \mathrm{ml}\right)+$ CTZ $(8$ $\mu \mathrm{g} / \mathrm{ml})$; Group D: $1.5 \mathrm{ml}$ of macrophage suspension $\left(10^{5} / \mathrm{ml}\right)+0.8 \mathrm{ml}$ of $S$. Typhimurium cell suspension $\left(10^{7} / \mathrm{ml}\right)+$ CFS $(80 \mathrm{AU} / \mathrm{ml})+\mathrm{CTZ}(2 \mu \mathrm{g} / \mathrm{ml})$ for $16 \mathrm{~h}$ in a six-well tissue culture plate at $37^{\circ} \mathrm{C}$ in $\mathrm{CO}_{2}$ incubator for $18 \mathrm{hrs}$. After incubation, lysis buffer $(20 \mathrm{mM}$ Tris- $\mathrm{HCl}, 150 \mathrm{mM} \mathrm{NaCl}, 1 \mathrm{mM}$ EDTA, 1\% Triton $\mathrm{X}-100,1 \mathrm{mM}$ PMSF) was added (1:1 ratio) to all the wells and the plate was further incubated at $4^{\circ} \mathrm{C}$ for 20 min. Reaction mixtures form each well were centrifuged (2,000 rpm, $15 \mathrm{~min})$ and supernatant thus obtained was used to study the following:

\section{Extent of lipid peroxidation}

Quantitative measurement of lipid peroxidation in the culture supernatants of macrophages was performed as described by us earlier [22]. The results were expressed as nanomoles of MDA per milligram of protein, using the molar extinction coefficient of chromophore $\left(1.56 \times 10^{5} \mathrm{M}^{-1} \mathrm{~cm}^{-1}\right)$. Protein content of the samples was estimated by the method as described by Lowry et al. [23].

\section{Estimation of nitrite concentration}

The amount of nitric oxide in cell-free supernatant was determined by slight modification of the method of Green et al. [24] as described by us earlier [25]. $100 \mu \mathrm{l}$ aliquots of sample were mixed with $400 \mu \mathrm{l}$ of distilled water and $500 \mu \mathrm{l}$ of Griess reagent. The reaction mixture was incubated at room temperature for $10 \mathrm{~min}$. 
(in dark) and optical density was measured at $546 \mathrm{~nm}$. Nitrite was quantified using standard graph of sodium nitrite.

\section{Statistical analysis}

Results were expressed as mean \pm standard deviation (SD). The inter group variation was assessed by one way analysis of variance (ANOVA) followed by Fischer's LSD test. Statistical significance of the results was calculated to at least $\mathrm{P}<0.05$.

\section{Results}

Antibiotic sensitivity pattern of Lactobacilli and $S$. Typhimurium

A compatible probiotic-antibiotic combination was found to be that of L. plantarum and co-trimoxazole. $S$. Typhimurium was found to be sensitive to co-trimoxazole while amongst the three Lactobacilli tested, L. plantarum was found to be resistant to the same (Table 1).

\section{Agar well diffusion assay (agar-WDA)}

The sensitivity of $S$. Typhimurium and resistance of L. plantarum to co-trimoxazole was further confirmed by agar-WDA. A clear zone of inhibition $(15 \mathrm{~mm})$ of growth of $S$. Typhimurium (Figure 1A) could be observed while L. plantarum exhibited complete resistance to co-trimoxazole (Figure 1B). These observations indicated the feasibility of using CFS of L. plantarum in conjunction with co-trimoxazole against $S$. Typhimurium NCTC74.

\section{Quantification of the antagonistic activity of $L$. plantarum cell-free supernatant (CFS)}

A clear zone of growth inhibition could be observed around the wells containing CFS indicating that L. plantarum was inhibitory to the growth of $S$. Typhimurium.
The maximum dilution of the cell-free supernatant that produced a minimum of antibacterial zone was 1: 1600 . It was therefore estimated that the antagonistic activity of the cell-free supernatant was $1600 \mathrm{AU} / \mathrm{ml}$.

\section{Agar-WDA}

When the wells were filled with $12 \mathrm{AU} / \mathrm{ml}, 16 \mathrm{AU} / \mathrm{ml}$ and $20 \mathrm{AU} / \mathrm{ml}$ of CFS alone, the zone sizes obtained were $22 \mathrm{~mm}, 28 \mathrm{~mm}$ and $33 \mathrm{~mm}$ respectively. Similarly, co-trimoxazole at 10, 20 and $30 \mu \mathrm{g} / \mathrm{ml}$ concentrations produced a zone size of 24,31 and $40 \mathrm{~mm}$ respectively. However, interestingly in combination at half the concentrations of both agents i.e. (CTZ $(5 \mu \mathrm{g} / \mathrm{ml})+$ CFS (6 AU/ml); CTZ $(10 \mu \mathrm{g} / \mathrm{ml})+$ CFS $(8 \mathrm{AU} / \mathrm{ml}) ; \mathrm{CTZ}$ $(15 \mu \mathrm{g} / \mathrm{ml})+\mathrm{CFS}(10 \mathrm{AU} / \mathrm{ml})$, the zone sizes were 32 , 34 and $44 \mathrm{~mm}$ respectively (Figure $2 \mathrm{~A}-\mathrm{C}$ are representative figures). The observed zone of growth-inhibition of Salmonella Typhimurium indicated synergy between the two as the dose required to give the same antibacterial effect in terms of size of zone of inhibition was reduced to approximately half when CFS and co-trimoxazole were used in combination as compared to when used individually at different concentrations.

\section{MICs of co-trimoxazole and CFS}

The MICs of cotrimoxazole and CFS against Salmonella Typhimurium were evaluated to be $8 \mu \mathrm{g} / \mathrm{ml}$ and $640 \mathrm{AU} / \mathrm{ml}$ respectively.

\section{Fractional inhibitory concentrations (FIC) of co- trimoxazole and CFS}

The inhibitory activity of the combination of co-trimoxazole and CFS was determined by the FIC index at 64 different combinations. FICI index was $\leq 0.5$ indicating that there is synergistic effect of the combination. When used together, co-trimoxazole and CFS inhibited the

Table 1 Antibiotic susceptibility pattern of test Lactobacilli strains i.e L. plantarum, L. casei, L. acidophilus and indicator strain $S$. Typhimurium as determined by disc-diffusion technique

\begin{tabular}{|c|c|c|c|c|c|}
\hline \multirow[t]{2}{*}{ Antibiotics } & \multirow[t]{2}{*}{ Conc. ug/disc } & \multicolumn{3}{|c|}{ Test Lactobacillus strains } & \multirow[t]{2}{*}{ Indicator strain S. Typhimurium } \\
\hline & & L. acidophilus & L. casei & L. plantarum & \\
\hline Norfloxacin & 10 & $\mathrm{R}$ & $\mathrm{R}$ & $\mathrm{R}$ & S \\
\hline Cotrimoxazole & 25 & $S$ & $S$ & $R$ & $S$ \\
\hline Gentamycin & 10 & S & $\mathrm{R}$ & S & S \\
\hline Ampicillin & 25 & $\mathrm{R}$ & S & $\mathrm{R}$ & $\mathrm{R}$ \\
\hline Cephalexin & 30 & S & S & S & S \\
\hline Amikacin & 30 & S & $\mathrm{R}$ & $\mathrm{R}$ & S \\
\hline Cefoxitin & 10 & $\mathrm{R}$ & $\mathrm{R}$ & $\mathrm{R}$ & $\mathrm{R}$ \\
\hline Chloramphenicol & 30 & $\mathrm{~S}$ & $\mathrm{~S}$ & $R$ & S \\
\hline Cefuroxine & 30 & $\mathrm{~S}$ & $\mathrm{R}$ & $\mathrm{R}$ & $\mathrm{S}$ \\
\hline Augmentin & 10 & $\mathrm{R}$ & $\mathrm{R}$ & $\mathrm{R}$ & $\mathrm{R}$ \\
\hline Tetracycline & 25 & $S$ & $S$ & S & S \\
\hline
\end{tabular}

S-sensitive R-resistant. 


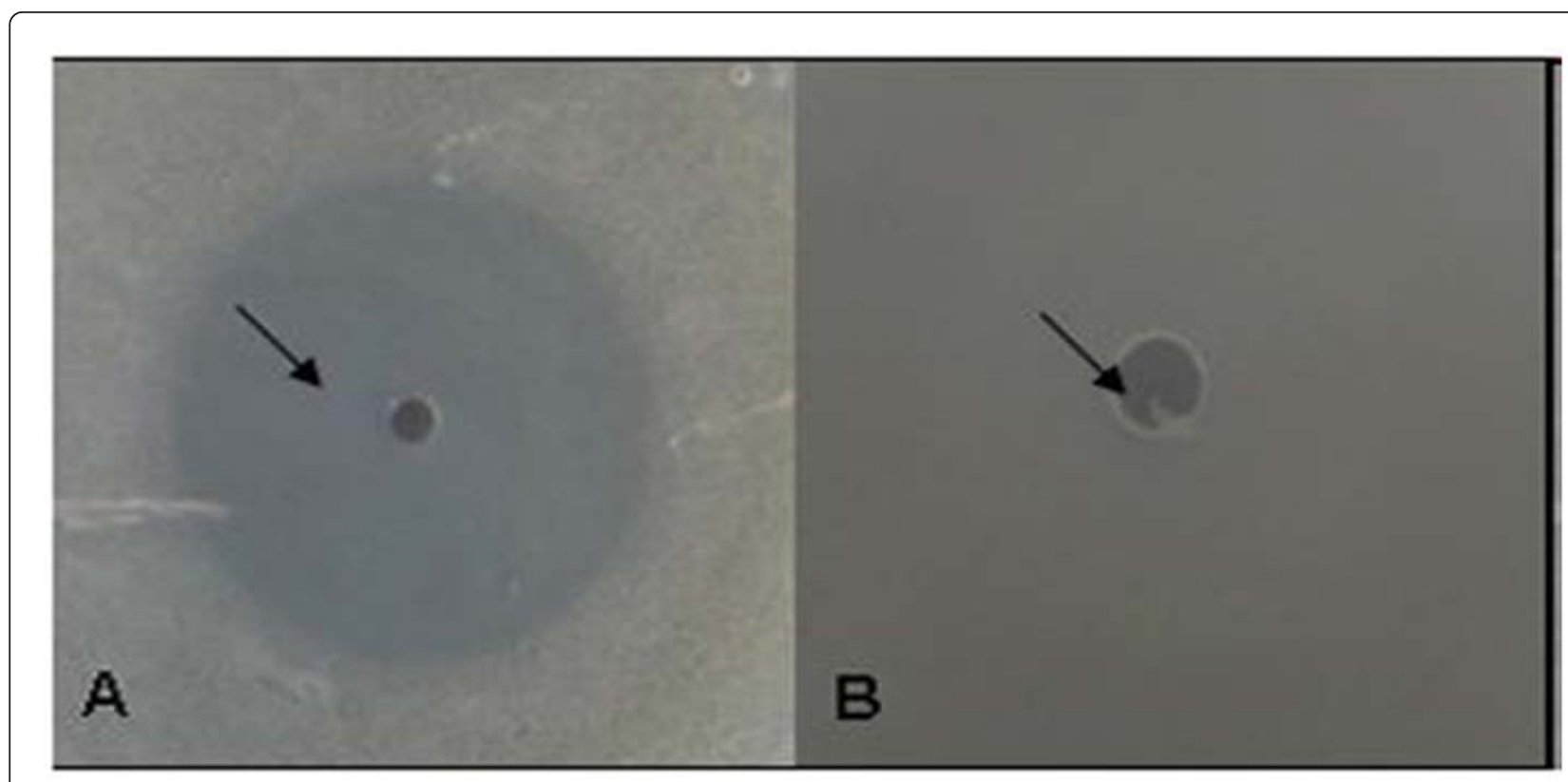

Figure 1 Agar-well diffusion assay. (A) Zone of inhibition of growth of S. Typhimurium produced by co-trimoxazole (10 $\mu \mathrm{g} / \mathrm{ml})$ (B) Resistance exhibited by L. plantarum to co-trimoxazole $(10 \mu \mathrm{g} / \mathrm{ml})$ (agar-well diffusion assay).

growth at four fold $(2 \mu \mathrm{g} / \mathrm{ml})$ and eight fold $(80 \mathrm{AU} / \mathrm{ml})$ lower concentrations than when applied alone.

\section{Time Kill Assay}

After 48 hours, CFS $(80 \mathrm{AU} / \mathrm{ml})$ and CTZ $(2 \mu \mathrm{g} / \mathrm{ml})$ separately gave a decrease of $5.78 \mathrm{log}$ units and $6.5 \mathrm{log}$ units respectively as compared to control $(48 \mathrm{~h})$. However, when used in combination, (CFS $(80 \mathrm{AU} / \mathrm{ml})+$ CTZ $(2 \mu \mathrm{g} / \mathrm{ml})$, a decrease of $7 \log$ units was observed after $48 \mathrm{~h}$ (Figure 3 ) indicating the synergetic effect.

\section{Effect on intracellular killing of S. Typhimurium}

The mean percentage intracellular killing in presence of CFS alone at 30, 60 and 90 minutes was $13.7 \%, 35 \%$ and $48.75 \%$ respectively, at $\mathrm{p}<0.05$. Similarly, when infected macrophages were treated with co-trimoxazole alone, the mean intracellular killing was $21.25 \%, 42.5 \%$ and $63.75 \%$ at 30,60 and 90 minutes respectively ( $<$ < 0.01 ). A higher intracellular killing was observed when infected macrophages were treated with co-trimoxazole in conjunction with CFS. In this case, the killing was

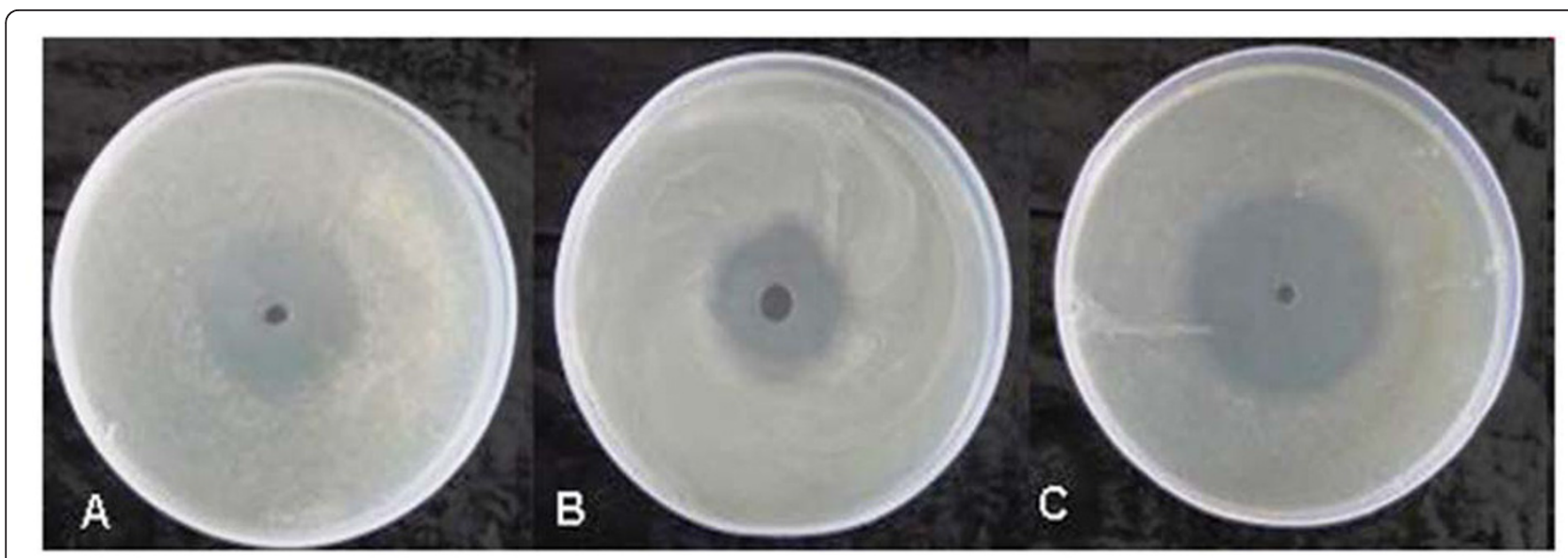

Figure 2 (A-C)-Synergy exhibited by CTZ and CFS in terms of size of zones of inhibition produced when used separately and in combination against $S$. Typhimurium as determined by agar-WDA. (A) CTZ $(10 \mu \mathrm{g} / \mathrm{ml})$ (B) CFS (12 AU/ml) (C) CFS (6 AU/ml) + CTZ $(5 \mu \mathrm{g} / \mathrm{ml})$. 


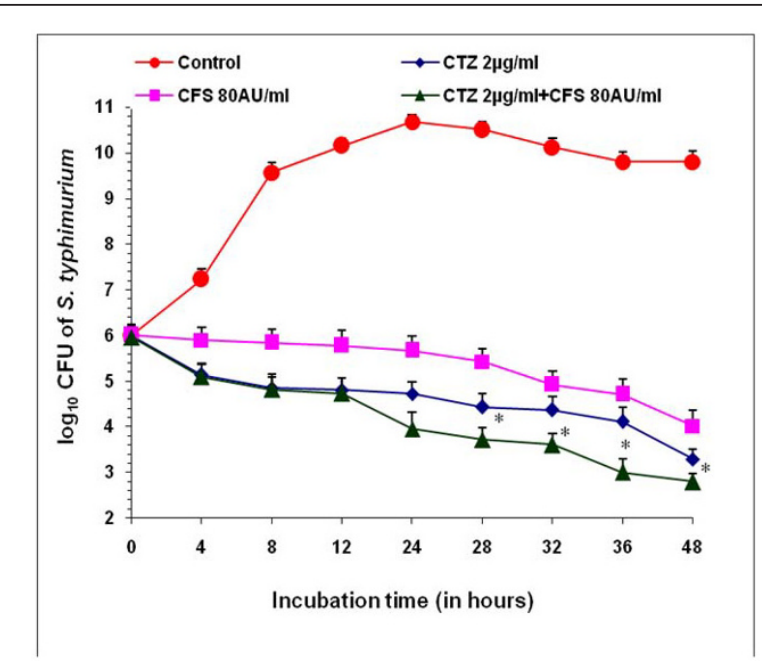

Figure 3 Time-kill assay. $\log _{10}$ CFU of Salmonella Typhimurium NCTC 74 at various time intervals in presence of cotrimoxazole (2 $\mu \mathrm{g}), \mathrm{CFS}(80 \mathrm{AU} / \mathrm{ml})$ alone and in combination i.e CTZ $(2 \mu \mathrm{g} / \mathrm{ml})+$ CFS $(80 \mathrm{AU} / \mathrm{ml})$. Values are expressed as mean \pm S.D. of three individual values. ${ }^{*} \mathrm{p}<0.05 \mathrm{vs}$. CTZ $(10 \mathrm{ug} / \mathrm{ml})$ and CFS (12 AU/ml).

found to be $25 \%(+\mathrm{p}<0.01), 53.75 \%(+\mathrm{p}<0.01)$ and 92.3\% ( $\neq \mathrm{p}<0.001)$ at $30^{\prime}, 60^{\prime}$ and $90^{\prime}$ respectively (Table 2). On the other hand, the intracellular killing in untreated macrophages was $11.2 \%, 27.5 \%$ and $43.75 \%$ at 30,60 and 90 minutes respectively. The results indicate that both CFS and co-trimoxazole might act cooperatively leading to an enhanced killing of intracellular S. Typhimurium.

\section{Estimation of lipid peroxidation (MDA) levels}

No significant decrease in the levels of MDA was observed when macrophages were interacted with $S$. Typhimurium in the presence of CFS and co-trimoxazole alone as compared to the normally interacted macrophages (in absence of any antimicrobial agent).
However, MDA levels were significantly reduced where macrophages were interacted with $S$. Typhimurium in the presence of CFS and co-trimoxazole in combination (Figure 4).

\section{Estimation of nitrite levels}

Significant decrease $(\mathrm{p}<0.01)$ in the levels of nitrite reduced by macrophages was observed in presence of cotrimoxazole as compared to the normal infected macrophages. Similarly, nitrite levels of infected macrophages were significantly reduced in the presence of CFS also but to a lesser extent $(\mathrm{p}<0.05)$ (Figure 5). However, a more pronounced effect $(\mathrm{p}<0.01)$ was observed when macrophages were interacted with $S$. Typhimurium in the presence of both CFS and co-trimoxazole together.

\section{Discussion}

Therapy with antimicrobial combinations has been in use for a long time and is often applied to take advantage of different mechanisms of action of the agents involved [13]. Co-trimoxazole, a combination of a sulfamethoxazole with trimethoprim, is a synergistic combination, which has been used to treat Salmonellosis [26]. However, some Salmonella strains have been reported to develop resistance to co-trimoxazole $[27,28]$. Consequently, the study of co-trimoxazole in combination with probiotics might prove useful as frequency of development of microbial resistance to the combination is likely to be lower than it would be to either agent, if used alone. Therefore, the current study was carried out to detect whether cell free supernatant from L. plantarum in combination with co-trimoxazole therapy would have higher antimicrobial activity against S. Typhimurium.

Keeping in view the application of probiotics to be used in conjunction with an antibiotic, the first criteria which a probiotic strain needs to fulfil is that it should

Table 2 Effect of CTZ and CFS on intracellular killing of Salmonella Typhimurium NCTC 74 (assessed by isolating murine peritoneal macrophages from Balb/c mice and interacting them with Salmonella in presence of CFS and CTZ separately and in combination)

\begin{tabular}{|c|c|c|c|c|c|c|c|c|}
\hline \multirow[t]{3}{*}{$\begin{array}{l}\text { Duration of intra-cellular incubation } \\
\text { (min.) }\end{array}$} & \multicolumn{4}{|c|}{ CFU of S. Typhimurium } & \multicolumn{4}{|c|}{$\begin{array}{l}\text { Mean Percentage Intracellular Killing }\{\text { (No- } \\
\left.\left.\qquad N_{t} / N_{0}\right) \times 100\right\}\end{array}$} \\
\hline & \multirow[t]{2}{*}{$\begin{array}{l}\text { Untreated } \\
\text { Macrophages }\end{array}$} & \multicolumn{3}{|c|}{ Treated Macrophages } & \multirow[t]{2}{*}{$\begin{array}{c}\text { Untreated } \\
\text { Macrophages }\end{array}$} & \multicolumn{3}{|c|}{$\begin{array}{c}\text { Treated } \\
\text { Macrophages }\end{array}$} \\
\hline & & CTZ & CFS & $\begin{array}{c}\mathrm{CTZ} \\
+ \\
\text { CFS }\end{array}$ & & $\mathrm{CTZ}$ & CFS & $\begin{array}{c}\text { CTZ } \\
+ \\
\text { CFS }\end{array}$ \\
\hline $0\left(N_{0}\right)$ & $80 \times 10^{7}$ & - & - & - & & - & - & - \\
\hline 30 & $71 \times 10^{7}$ & $63 \times 10^{7 *}$ & $69 \times 10^{7}$ & $60 \times 10^{7 *+}$ & 11.2 & 21.25 & 13.7 & 25 \\
\hline 60 & $58 \times 10^{7}$ & $46 \times 10^{7 *}$ & $52 \times 10^{7 *}$ & $37 \times 10^{7 *+}$ & 27.5 & 42.5 & 35 & 53.75 \\
\hline 90 & $45 \times 10^{7}$ & $29 \times 10^{7 *}$ & $41 \times 10^{7 *}$ & $6.1 \times 10^{7 *} \neq$ & 43.75 & 63.75 & 48.75 & 92.3 \\
\hline
\end{tabular}

Co-trimoxazole-CTZ; Cell free supernatant from L. plantarum - CFS. 


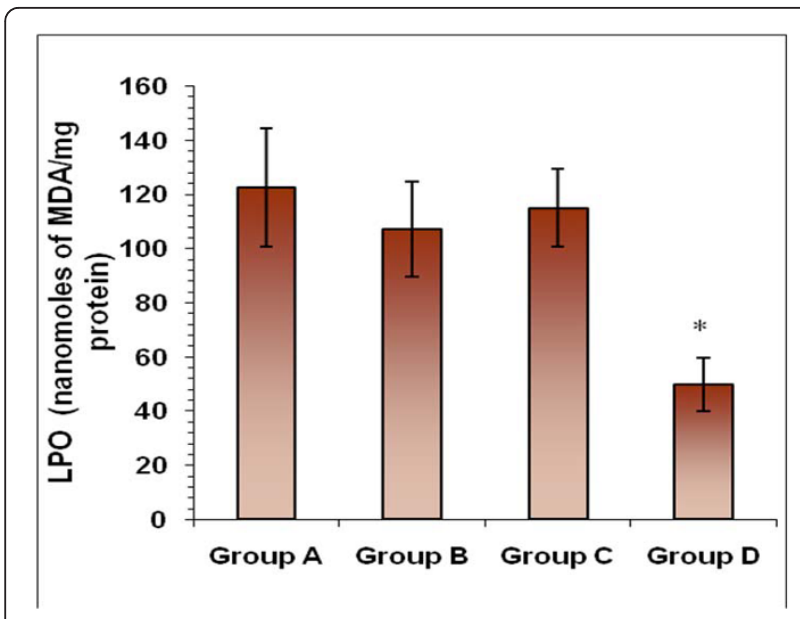

Figure 4 Estimation of lipid peroxidation (MDA) levels. Effect on the levels of lipid-peroxidation (in terms of MDA levels) of macrophages when infected with S. Typhimurium in presence of cotrimoxazole and CFS alone and in combination. Values are expressed as mean \pm S.D. of four individual values. ${ }^{*} p<0.05$ vs. Group A.

be resistant to that particular antibiotic to avoid the direct killing of the probiotic strain. After evaluating the resistance and sensitivity of L. plantarum and S. Typhimurium respectively to co-trimoxazole, the combination of cell free supernatant from L. plantarum and co-trimoxazole was further tested to evaluate the synergistic effect against $S$. Typhimurium. The results exhibited synergy between the two agents as the dose required to give the same antibacterial effect in terms of size of zone of inhibition and colony forming units was reduced to approximately half as compared to when used individually at higher doses. CFS contains several antimicrobials

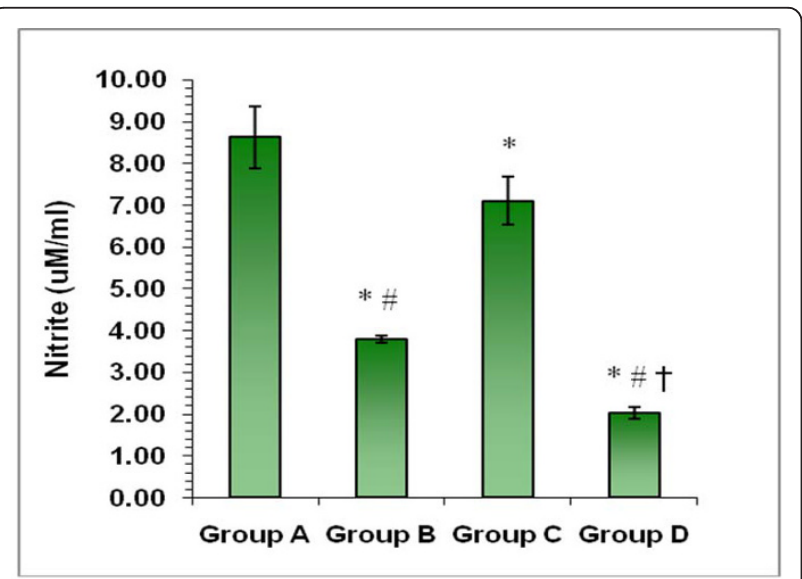

Figure $\mathbf{5}$ Estimation of nitrite levels. Effect on the levels of nitrite levels of macrophages when infected with $S$. Typhimurium in the presence of co-trimoxazole, CFS alone or in combination. ${ }^{*} p<0.05$ vs. Group A; ${ }^{\neq} p<0.05$ vs. Group $C_{;}{ }^{\dagger} p<0.05$ vs. Group B.
[29], lactic and non-lactic acids as well as hydrogen peroxide which kill pathogens [30] while co-trimoxazole is known to interfere with bacterial folate synthesis [31]. These two mechanisms might have acted cooperatively with each other leading to a higher bactericidal effect of the combination. FIC index also further substantiated the synergism between the two.

The in-vitro synergism observed between CFS and cotrimoxazole prompted us to investigate the ex-vivo synergistic efficacy in terms of macrophage functions keeping in view the intracellular survival ability of Salmonella. It is also known that $S$. Typhimurium infection of macrophages increases intracellular reactive oxygen intermediates (ROIs), which in turn increase the expression of other antimicrobial factors [32]. Thus, significantly enhanced killing of the Salmonella in the presence of CFS and co-trimoxazole, in combination, might be due to the cooperativity between the macrophage antibacterial effectors and the antimicrobial combinations used [14]. Corroborating with the present data, earlier studies have also shown that cell free supernatants and/or extracts from lactic acid producing bacteria may activate macrophages in-vitro thereby resulting in augmented phagocytic activity [33,34].

Further, a significant decrease in extent of lipid peroxidation (in terms of MDA level) was also observed in the presence of CFS and co-trimoxazole both. This indicated that the combination of cell free supernatant and co-trimoxazole may exhibit the synergistic effect by scavenging free radicals thereby providing protection against oxidative damage [7]. In support of our findings, Lin and Yen [35] have also reported the inhibition of lipid peroxidation by cell free extracts of $L$. acidophilus and B. longum using lipid model systems.

Nitric oxide is an important signalling molecule which acts in many tissues to regulate diverse range of physiological process. The estimation of nitrite is an indirect measure of nitric oxide content. In the present study also, a significant decrease in nitrite levels was observed when macrophages were interacted with $S$. Typhimurium in presence of both co-trimoxazole and CFS as compared to infected macrophages in the absence of the agents. It may be attributed to the enhanced ability of probiotics to attenuate TNF- $\alpha$ or TNF- $\alpha$ stimulated IL- 8 production in presence of cotrimoxazole, which might result in further decrease of NO levels [30,36].

\section{Conclusions}

In conclusion, the in-vitro and ex-vivo studies clearly indicate that cell-free extract from L. plantarum and co-trimoxazole act synergistically against Salmonella Typhimurium. Positive effects of this antimicrobial combination against Salmonella points towards possible 
in-vivo use of the probiotic L. plantarum with co-trimoxazole for effective treatment of Salmonella infections

\section{Authors' contributions}

PR conceived, supervised the study and finalized the manuscript. SP and PK performed the experiments and contributed to the writing of the manuscript. All authors read and approved the final manuscript.

\section{Competing interests}

The authors declare that they have no competing interests.

Received: 14 October 2010 Accepted: 27 February 2011

Published: 27 February 2011

\section{References}

1. Henderson DK, Levy SB, editors: Resistant organisms: global impact on continuum of care. International Congress and Symposium Series \#220 New York, NY: Royal Society of Medicine; 1997.

2. Birosova L, Mikulasova M: Development of triclosan and antibiotic resistance in Salmonella enterica serovar Typhimurium. J Med Microbiol 2009, 58(4):436-41.

3. Hammad AM, Shimamato T: Towards a compatible probiotic-antibiotic therapy: assessment of antimicrobial resistance in the Japanese probiotics. J Appl Microbiol 2010, 109(4):1349-13603.

4. Ibezim EC, Esimore CO, Obodo CE, Nnamani PO, Brown SA, Onyishi IV: A study of the in-vitro interaction of co-trimoxazole and ampicillin using the checker board method. Afr J Biotechnol 2006, 5(13):1284-1288.

5. Truusalu K, Mikelsaar RH, Naaber P, Karki T, Kullisaar T, Zilmer M, et al: Eradication of Salmonella Typhimurium infection in a murine model of typhoid fever with the combination of probiotic Lactobacillus fermentum ME-3 and ofloxacin. BMC Microbiol 2008, 8:132.

6. Bergonzelli GE, Blum S, Brussow H, Theulaz Cl: Probiotics as a treatment strategy for gastrointestinal diseases. Digestion 2005, 72:57-68.

7. Rishi P, Mavi SK, Bharrhan S, Shukla G, Tewari R: Protective efficacy of probiotics alone or in conjunction with a prebiotic in Salmonellainduced liver damage. FEMS Microbiol Ecol 2009, 69:222-230.

8. Rishi P, Kaur S, Bhalla MPS, Preet S, Tiwari RP: Selection of probiotic Lactobacillus acidophilus and its prophylactic activity against murine Salmonellosis. Int J Pro Pre 2008, 3(2):89-98.

9. Marteau PR, de Vrese M, Cellier CJ, Schrezenmeir J: Protection from gastrointestinal diseases with the use of probiotics. Am J Clin Nutr 2001 73:430-436.

10. Sullivan A, Nord CE: Probiotics and gastrointestinal diseases. J Intern Med 2005, 257:78-92.

11. Szajewska H, Setty M, Mrukowicz J, Guandalini S: Probiotics in gastrointestinal diseases in children: hard and not-so-hard evidence of efficacy. J Pediatr Gastroenterol Nutr 2006, 42:454-475.

12. Zou J, Dong J, Yu X: Meta-analysis: Lactobacillus containing quadruple therapy versus standard triple first-line therapy for Helicobacter pylori eradication. Helicobacter 2009, 14:97-107.

13. Rybak JM, Grath MJB: Combination antimicrobial therapy for bacterial infections, Guidelines for the Clinician. Drugs 1996, 52(3):390-402.

14. Preet S, Verma I, Rishi P: Cryptdin-2: a novel therapeutic agent for experimental Salmonella Typhimurium infection. J Antimicrob Chemother 2010, 65:991-994.

15. Piddock LJV, Ricci V, McLaren I, Griggs DJ: Role of mutation in the gyrA and par $C$ genes of nalidixic-acid resistant Salmonella serotypes isolated from animals in the United Kingdom. J Antimicrob Chemother 1998, 41:635-641.

16. Bauer AW, Kirby MM, Sherris JC, Tuurck M: Antimicrobial susceptibility testing by a standardised single disc method. Am J Clin Path 1966, 45:493-496.

17. NCCLS (National Committee for clinical laboratory standards): NCCLS document M-100-S9, Performance standards for antimicrobial susceptibility testing, $9^{\text {th }}$ information supplement. NCCLS: Wayne Pa.

18. Tagg JR, McGiven AR: Assay system for bacteriocins. Appl Microbiol 1971, 21:943-948.
19. Ogunbanwo ST, Sanni Al, Onilude AA: Characterization of bacteriocin produced by Lactobacillus plantarum F1 and Lactobacillus brevis OG1. Afr J Biotechnol 2003, 2(8):219-227.

20. He L, Chen W: Synergetic activity of nisin with cell-free supernatant of Bacillus licheniformis ZJU12 against food borne bacteria. Food Res Int 2006, 39:905-909.

21. White RL, Burgess DS, Manduru M, Bosso JA: Comparison of three different in vitro methods of detecting synergy: time-kill, checkerboard, and E test. Antimicrob Agents Chemother 1996, 40:1914-1918.

22. Chanana V, Majumdar S, Rishi P: Tumour necrosis factor alpha mediated apoptosis in murine macrophages by Salmonella enterica serovar Typhi under oxidative stress. FEMS Immuno Med Microbiol 2006, 47:278-286.

23. Lowry OH, Rosbrough NJ, Farr AL, Randall RJ: Protein estimation with Folin's reagent. J Biol Chem 1951, 193:265-275.

24. Green LC, Wagner DA, Glogowski J, Shipper PL, Wishnok J, Raannerbaun SR: Analysis of nitrate, nitrite and $15 \mathrm{~N}$ nitrate in biological fluids. Anal Biochem 1982, 126:121-158.

25. Chanana $V$, Ray $P$, Rishi DB, Rishi P: Reactive nitrogen intermediates and monokines induce caspase-3 mediated macrophage apoptosis by anaerobically stressed Salmonella typhi. Clin Exp Immunol 2007, 150(2):368-374.

26. Mandomando I, Macete E, Sigauque B, Morais L, Quinto L, Sacarlal J, et al: Invasive non-typhoidal Salmonella in Mozambican children. Trop Med Int Health 2009, 14(12):1467-74.

27. Mengo DM, Kariuk S, Muigai AWT, Revathi GN: Trends in Salmonella enterica serovar Typhi in Nairobi, Kenya from 2004 to 2006. J Infect Dev Ctries 2010, 4(6):393-396.

28. Singh BR, Jyoti J, Chandra M, Babu N, Sharma GJ: Drug resistance patterns of Salmonella isolates of equine origin from India. J Infect Dev Ctries 2009, 3(2):141-147.

29. Botes M, Loos B, van Reenen CA, Dicks LM: Adhesion of the probiotic strains Enterococcus mundtii ST4SA and Lactobacillus plantarum 423 to Caco- 2 cells under conditions simulating the intestinal tract, and in the presence of antibiotics and anti-inflammatory medicaments. Arch Microbiol 2008, 190(5):573-84.

30. Gopal PK, Prasad J, Smart J, Gill HS: In-vitro adherence properties of Lactobacillus rhamnosus DR20 and Bifidobacterium lactis DR10 strains and their antagonistic activity against an enterotoxigenic Escherichia coli. Int J Food Microbiol 2001, 67(3):207-16.

31. Lee I, Turner M, Lee CC: Acute patchy exanthematous pustulosis caused by sulfamethoxazole-trimethoprim. J Am Acad Dermatol 2010, 63(2):41-43.

32. Rosenberger CM, Gallo RL, Finalay BB: Interplay between antibacterial effcetors: A macrophage antimicrobial peptide impairs intracellular Salmonella replication. Proc Natl Acad Sci 2004, 101(8):2422-2427.

33. Hatcher GE, Lambrecht RS: Augmentation of macrophage phagocytic activity by cell-free extracts of selected lactic acid-producing bacteria. J Dairy Sci 1993, 76:2485-2492.

34. Vincenti JE: The influence of cell-free Lactobacillus rhamnosus GG supernatant on the phagocytic activity of macrophages. Bio Horizons 2010, 3(2):105-112.

35. Lin MY, Yen CL: Inhibition of lipid peroxidation by Lactobacillus acidophilus and Bifidobacterium longum. J Agr Food Chem 1999, 47(9):3661-3664

36. Madsen $K$, Cornish A, Soper P, Yachimec C, Doyle J, Jewell L, De Simone C: Probiotic bacteria enhance murine and human intestinal epithelial barrier function. Gastroenterol 2001, 121:580-581.

doi:10.1186/1476-0711-10-9

Cite this article as: Rishi et al.: Effect of $L$. plantarum cell-free extract and co-trimoxazole against Salmonella Typhimurium: a possible adjunct therapy. Annals of Clinical Microbiology and Antimicrobials 2011 10:9. 